OPEN ACCESS

Edited by:

Charles R. Rinaldo,

University of Pittsburgh,

United States

Reviewed by:

Christiane Moog,

Institut national de la santé et de la recherche médicale

(INSERM), France

Marie Pancera,

Fred Hutchinson Cancer

Research Center, United States

Juan Pablo Jaworski,

Consejo Nacional de

Investigaciones Cientificas y Técnicas (CONICET), Argentina

${ }^{*}$ Correspondence:

Christophe Guillon

christophe.guillon@ibcp.fr

tThese authors have contributed equally to this work.

Specialty section: This article was submitted to HIV and AIDS,

a section of the journal

Frontiers in Immunology

Received: 23 March 2017

Accepted: 16 June 2017

Published: 30 June 2017

Citation:

Verrier B, Paul S, Terrat C, Bastide L,

Ensinas A, Phelip C, Chanut B,

Bulens-Grassigny L, Jospin F and

Guillon C (2017) Exploiting Natural

Cross-reactivity between Human Immunodeficiency Virus (HIV)-1 p17

Protein and Anti-gp41 2F5

Antibody to Induce HIV-1

Neutralizing Responses In Vivo.

Front. Immunol. 8:770.

doi: 10.3389/fimmu.2017.00770

\section{Exploiting Natural Cross-reactivity between Human Immunodeficiency Virus (HIV)-1 p17 Protein and Anti- gp41 2F5 Antibody to Induce HIV-1 Neutralizing Responses In Vivo}

\author{
Bernard Verrier ${ }^{1 \dagger}$, Stéphane Paul't, Céline Terrat ${ }^{1}$, Liza Bastide ${ }^{3}$, Agathe Ensinas ${ }^{1,2}$, \\ Capucine Phelip ${ }^{1}$, Blandine Chanut ${ }^{2}$, Laura Bulens-Grassigny ${ }^{1,3}$, Fabienne Jospin ${ }^{2}$ \\ and Christophe Guillon ${ }^{3 *}$ \\ ${ }^{1}$ Colloidal Vectors and Tissue Transport, UMR5305, Institut de Biologie et Chimie des Protéines, Université de Lyon, CNRS, \\ Lyon, France, ${ }^{2}$ Groupe sur l'Immunité des Muqueuses et Agents Pathogènes, EA3064, Faculté de Médecine Jacques \\ Lisfranc, Université de Lyon, Saint-Etienne, France, ${ }^{3}$ Retroviruses and Structural Biochemistry, UMR5086, Institut de Biologie \\ et Chimie des Protéines, Université de Lyon, CNRS, Lyon, France
}

Anti-p17 antibodies are able to neutralize human immunodeficiency virus (HIV) entry in a mouse model. In this study, we identified a region of sequence similarity between the epitopes of anti-p17 neutralizing antibodies and anti-gp41 neutralizing 2F5 antibody and verified cross-reactivity between $\mathrm{p} 17$ and $2 \mathrm{~F} 5$ in vitro. The $\mathrm{p} 17$ sequence was modified to increase sequence identity between the p17 and 2F5 epitopes, which resulted in enhanced cross-reactivity in vitro. Immunogenicity of wild-type and modified p17 was characterized in a rabbit model. Both wild-type and mutated p17 induced anti-gp41 responses in rabbits; sera from these animals reacted with gp41 from different HIV clades. Moreover, introduction of the 2F5 sequence in p17 resulted in induction of antibodies with partially neutralizing activity. Based upon these data, we suggest that the natural cross-reactivity between HIV-1 p17 protein and 2F5 antibody can be exploited to induce antibodies with neutralizing activity in an animal model.

Keywords: human immunodeficiency virus-1, gp41, p17, neutralizing antibodies, cross-reactivity, antigen engineering

\section{INTRODUCTION}

Despite the high variability of human immunodeficiency virus (HIV), approximately $15-30 \%$ of infected patients develop broadly neutralizing antibodies (bnAbs) able to neutralize entry of the majority of HIV strains (1-3). In non-human primates, passive administration of such bnAbs protects animals from infection (4). Although several bnAbs have been characterized $(2,5)$, the method by which to induce such antibodies by vaccination remains an important issue $(3,6-9)$. Preclinical studies in various models suggest that sequential immunizations, with multiple injections and/or multiple antigens, may be one way to elicit bnAbs (10-12). However, current vaccine strategies have not yet been able to induce high bnAbs titers (13).

Another important target for HIV vaccination is the Gag polyprotein. The simian immunodeficiency virus Gag capsid subunit undergoes strong structural constraints, which limit its variability and, therefore, its ability to accumulate mutations in order to elude the host immune system (14). 
Indeed, broad cytotoxic T-lymphocyte (CTL) responses targeting Gag are associated with a low viral load in HIV-infected people (15-17), and induction of CTL responses against HIV-1 Gag could lead to elimination of HIV-1-infected cells and aid in control of viral dissemination (18). Moreover, antibody responses against the p17 subunit of Gag could block the pathogenic effects of extracellular p17 $(19,20)$.

As Gag proteins are not exposed on the virion surface, few studies have systematically explored the antibody responses induced by immunization with Gag proteins and their potential to inhibit HIV infection. However, cross-reactivity between p17 and gp41 can occur (21), and viral entry can be neutralized by antibodies against p17 (22). The p17 sequence, ELDKWRK, is part of the epitope of an anti-p17 antibody that neutralizes HIV entry (22), and a bnAb, 2F5, directed against the HIV gp41 envelope subunit, was identified in an infected individual $(23,24)$. Interestingly, this 2F5 antibody recognizes an epitope with the sequence ELDKWAS in the membrane proximal external region (MPER) of gp41 (24). This pentapeptide, ELDKW, is shared by HIV-1 p17 and the MPER of HIV-1 gp41, and is recognized by two neutralizing antibodies targeting p17 and gp41. However, the structure of the 2F5 antibody in complex with its epitope shows the AS residues of the 2F5 epitope ELDKWAS involved in the antibody/peptide interaction and in the conformation of the epitope (25).

In the present study, we demonstrated cross-reactivity between the anti-gp41 2F5 antibody and the wild-type p17 protein. We then introduced the entire ELDKWAS 2F5 epitope in the context of the ELDKW pentapeptide into p17 and evaluated cross-recognition in vitro. Finally, preliminary immunization experiments in an animal model confirmed the ability of p17 to induce anti-gp41 immune responses with neutralizing activities, which are improved by mutating p17.

\section{MATERIALS AND METHODS}

\section{p17 Constructs}

Amino acid sequences of the various constructs are described in Figures 1A,B. The wild-type gene (p17WT) from the pNL4-3. Luc. $\mathrm{R}^{-} . \mathrm{E}^{-}$plasmid (26) was amplified by PCR in-frame with a $\mathrm{C}$-terminal $6 \times$ His tag. The p17AS mutant was obtained from the p17WT coding sequence using Phusion polymerase (Finnzymes) and primers p17AS-R (5'-GATAAATGGGCAAGCATTC GGTTAAG- $3^{\prime}$ ) andp17AS-F(5'-CTTAACCGAATGCTTGCCCA TTTATC- $\left.3^{\prime}\right)$. The 17 constructs were inserted into the pRSET-B plasmid (Invitrogen) using NdeI/EcoRI restriction sites.

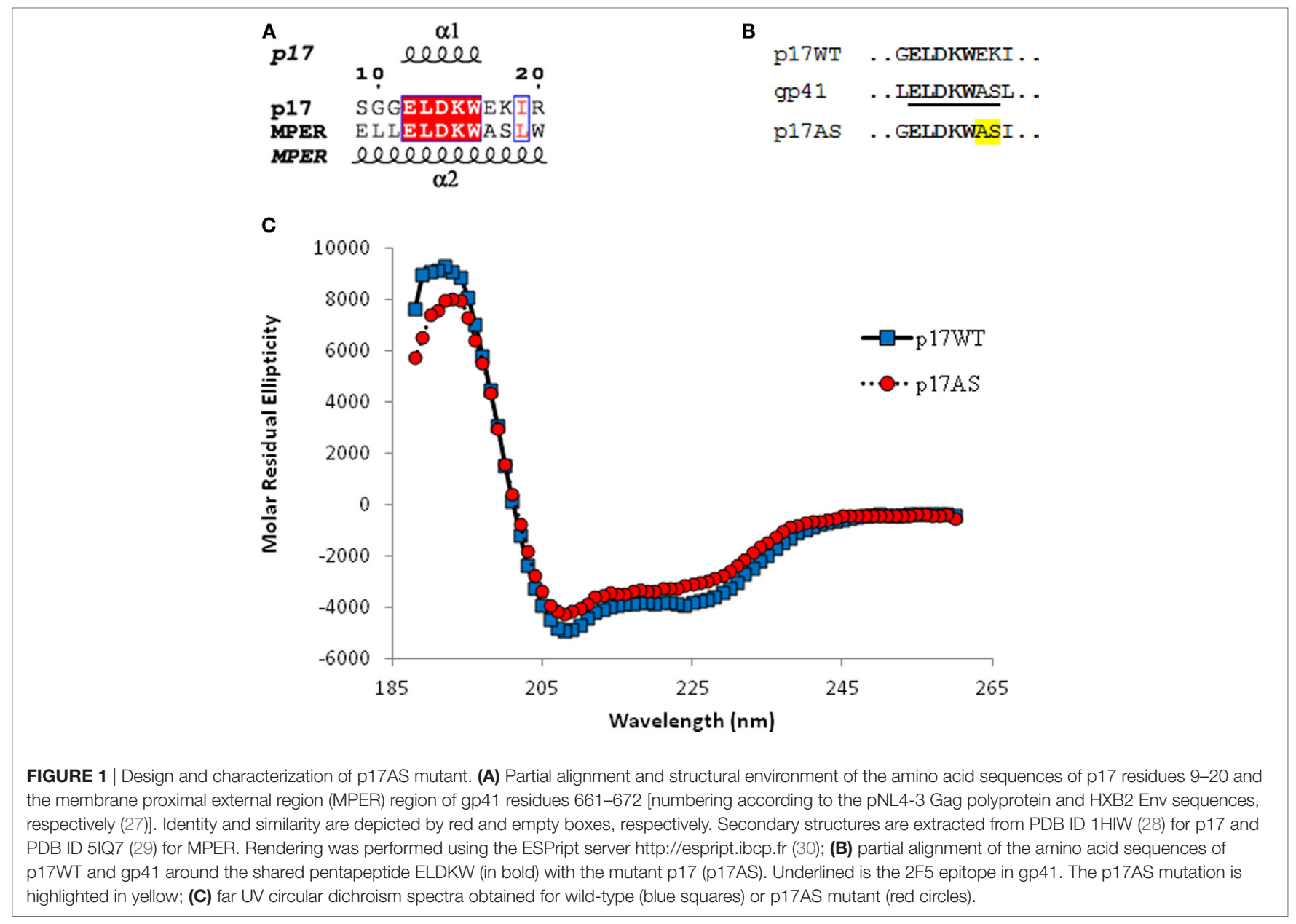




\section{Protein Expression, Purification, and Analysis}

The p17 constructs were expressed in BL21(DE3)pLys competent cells (Lucigen). Lysogeny broth $(250 \mathrm{ml})$ supplemented with $25 \mu \mathrm{g} / \mathrm{ml}$ ampicillin were seeded with an overnight preculture and incubated at $37^{\circ} \mathrm{C}$ with agitation. When $\mathrm{OD}_{600 \mathrm{~nm}} \approx 0.4$, protein expression was induced with $2 \mathrm{mM}$ isopropyl- $\beta$-D-1thiogalactopyranoside (Euromedex) and incubated for $5 \mathrm{~h}$ at $37^{\circ} \mathrm{C}$. Cultures were then centrifuged at $6,000 \times g$ for $5 \mathrm{~min}$, and pellets were stored overnight at $-20^{\circ} \mathrm{C}$.

Bacterial lysis and protein purification using Ni-TED resin (Macherey-Nagel) were performed as previously described (31), except lysis was performed by sonication of the pellet for $4 \times 1 \mathrm{~min} / \mathrm{g}$ with a Sonifier 250 sonicator (Brandson).

Following protein purity analysis with sodium dodecyl sulfate polyacrylamide gel electrophoresis (SDS-PAGE), elution fractions were pooled, dialyzed against $50 \mathrm{mM} 2$-( $N$-morpholino) ethanesulfonic acid (MES), $\mathrm{pH} 6$, overnight at $4^{\circ} \mathrm{C}$, and concentrated to $1 \mathrm{mg} / \mathrm{ml}$ according to the absorbance of the protein solution at $280 \mathrm{~nm}$, using a Vivaspin-PES $10 \mathrm{kDa}$ (Sartorius).

Circular dichroism spectra were recorded and processed using a Chirascan Dichrometer (Applied Photophysics) as described previously (32), with $150 \mu \mathrm{l}$ of protein at $0.2 \mathrm{mg} / \mathrm{ml}$ in $50 \mathrm{mM}$ MES pH 6.

\section{Enzyme-Linked Immunosorbent Assay (ELISA) Cross-reactivity}

Anti-p17 mouse monoclonal antibody 8E7A3 (isotype IgG1к) was obtained after immunization of mice with HIV Gag (not shown). Anti-gp41 2F5 human antibody (Polymun Scientific) and isotypic controls (anti-gp120 F105 and anti-Tat 11H6H1 for 2F5 and anti-p17, respectively) have been described elsewhere $(24,33,34)$. In order to evaluate cross-reactivity by ELISA, $100 \mathrm{ng} /$ well p17WT or p17AS protein in $1 \times$ phosphate-buffered saline (PBS) were coated onto 96-well plates (MaxiSorb, Nunc) overnight at $25^{\circ} \mathrm{C}$. Wells were saturated with $1 \times$ PBS- $10 \%$ horse serum (Thermo Fisher Scientific), incubated for $1 \mathrm{~h}$ at $37^{\circ} \mathrm{C}$, washed with $1 \times$ PBS- $0.05 \%$ Tween 20 (Sigma-Aldrich), and then incubated with serial dilutions of the antibodies in duplicate in PBS-10\% horse serum for $1 \mathrm{~h}$ at $37^{\circ} \mathrm{C}$. After washing, wells were incubated with $100 \mu \mathrm{l}$ horseradish peroxidase (HRP)-conjugated anti-human or anti-mouse IgG (Jackson Immunoresearch) diluted to $0.5 \mu \mathrm{g} / \mathrm{ml}$ in PBS-Tween and visualized using $\mathrm{BD}$-OptiEA reagent (BD Bioscience). OD values were measured at $450 \mathrm{~nm}$ with a reference at $620 \mathrm{~nm}$, using a Bio-Rad plate reader.

\section{Antigen Formulation and Rabbit Immunization}

The p17WT or mutant p17AS, diluted to $50 \mu \mathrm{g} / \mathrm{ml}$ in $1 \times$ PBS, were adsorbed on poly-lactic acid (PLA) nanoparticles for $2 \mathrm{~h}$ at $25^{\circ} \mathrm{C}$. Adsorption yield was calculated as previously described (35). After washing, antigen/PLA complexes were resuspended in $1 \times$ PBS to a final adsorbed protein concentration of $0.2 \mathrm{mg} / \mathrm{ml}$ according to the calculated yield. Formulations were stored at $4^{\circ} \mathrm{C}$ overnight before immunization the following day and remained homogeneous during all processes as verified by dynamic light scattering (data not shown).

Two groups of three rabbits (20-week-old New Zealand White female rabbits weighting $2.5 \mathrm{~kg}$ at the start of the experiment, Charles River Laboratories) were immunized subcutaneously with $100 \mu \mathrm{g}$ of formulated p17WT or p17AS proteins. Animals were immunized at day (d) $0, \mathrm{~d} 28$, and d63. Prior to each immunization and at $\mathrm{d} 14, \mathrm{~d} 42$, and $\mathrm{d} 77,5 \mathrm{ml}$ of sera were collected from each animal. Animals were sacrificed and exsanguinated at $\mathrm{d} 98$ when $3.5-5 \mathrm{ml}$ of serum were collected depending on the animals. Animals were housed and manipulated according to French standard regulatory ethical and welfare guidelines of the PLEXAN, Saint-Étienne (authorization no 42-218-0801) and approved by the relevant ethics committee (Comité d'Ethique en Expérimentation Animale de la Loire (CEEAL-UJM n 98), Faculté de Médecine Jacques Lisfranc, Saint-Étienne; reference 00811.02).

\section{Immunization Follow-up}

Anti-p17 IgG titers were quantified by ELISA, with the immunogen coated onto plates overnight at $100 \mathrm{ng} /$ well in PBS. After saturation and washes (described above in Section "Antigen Formulation and Rabbit Immunization"), sera were incubated at different concentrations for $1 \mathrm{~h}$ at $37^{\circ} \mathrm{C}$ and visualized using a HRP-conjugated anti-rabbit $\operatorname{IgG} \mathrm{Fc}$ fragment (P.A.R.I.S.) at $0.1 \mu \mathrm{g} / \mathrm{ml}$. Anti-gp41 titers were quantified under the same conditions, with wells coated with $100 \mathrm{ng} /$ well of recombinant HXB2 gp41 protein. Titers were measured as the reciprocal of the first dilution giving a negative signal $(<0.2 \mathrm{OD})$.

Sera from d98 diluted to 1:5,000 in PBS were evaluated for their reactivity against a panel of recombinant gp 41 fragments, which have been described previously $(36,37)$. Briefly, the proteins were coated at a concentration of $100 \mathrm{ng} /$ well overnight. After saturation and washes (described above in Section "EnzymeLinked Immunosorbent Assay (ELISA) cross-reactivity"), sera were incubated for $1 \mathrm{~h}$ at $37^{\circ} \mathrm{C}$ before being visualized with HRPconjugated anti-rabbit IgG Fc fragment (Bethyl), as previously described (35). The immunizing antigen and an aspecific control protein (bovine serum albumin) (Thermo Fisher Scientific) were used as positive and negative controls, respectively.

\section{Neutralization Assay}

IgG were purified from animal samples at $\mathrm{d} 98$ using the protein G HP SpinTrap/Ab SpinTrap kit (GE Healthcare), and IgG concentrations were measured using an IgG ELISA (37). Purified IgG did not show autoreactivity when tested at $20 \mu \mathrm{g} / \mathrm{ml}$ against 293T or Hep2 cells (data not shown). The neutralization assay was performed using T-cell line-adapted strain LAI (clade B) or primary isolates of clade A (92UG029), B (SF162, 92US660), and D (92UG001). Neutralizing activities of purified IgG were measured as described previously (37) on SupT1 cells or peripheral blood mononuclear cells (PBMCs) for the LAI strain and the primary isolates, respectively, in duplicate. PBMCs were isolated using standard Ficoll purification before being activated with phytohemagglutinin $\left(1 \mu \mathrm{g} / 10^{6}\right.$ cells $)$ for $48 \mathrm{~h}$. Purified rabbit IgG $(50 \mu \mathrm{l}$, concentrated to $100 \mu \mathrm{g} / \mathrm{ml})$ was 
incubated with $50 \mu \mathrm{l}$ virus for $3 \mathrm{~h}$ at $37^{\circ} \mathrm{C}$ prior to being added to $100 \mu \mathrm{l}$ cells $\left(3.10^{6}\right.$ cells $\left./ \mathrm{ml}\right)$ overnight. Cells where then washed with culture medium and incubated for 5 or 7 days (PBMCs and SupT1, respectively) before the supernatant was harvested. The concentration of p24 in the supernatant was determined using the p24 kit (InfYnity). Neutralization percentage was calculated as the reduction of $\mathrm{p} 24$ production compared to a control without rabbit IgG. Statistical analysis was performed using a Mann-Whitney $U$-test or a one-way analysis of variance (ANOVA) with a Bonferroni post-test (GraphPad 7.0), combining all individual data obtained for each group.

\section{RESULTS}

\section{Evidence of Cross-Recognition of p17 by 2F5 Antibody}

Alignment of the p17 N-terminal region with the MPER of gp41 containing the 2F5 epitope reveals the presence of a common pentapeptide, ELDKW, located in a similar $\alpha$-helical environment (Figure 1A). Based upon this data, we introduced mutations into p17WT to re-create the complete 2F5 cognate epitope, ELDKWAS, in p17 (Figure 1B). This mutation, termed p17AS, did not impair the structure of the 17 protein, as verified by circular dichroism (Figure 1C).

Both p17WT and p17AS reacted similarly with the anti-p17 antibody (Figures 2A,B). The p17WT protein was detected



FIGURE 2 | bnAb 2F5 cross-reacts with p17 in vitro. (A,B) Reactivity of p17WT (A) or p17AS mutant (B) against anti-p17 (black squares, plain lines) and anti-gp41 2F5 (white circles, dotted line) antibodies. Irrelevant antibody binding (F105 antibody) is displayed with purple triangles and lines. Values represent the mean value of four different experiments in duplicate, and error bars represent the SD of the same measures. with the anti-gp41 2F5 antibody (the cognate sequence contains ELDKW), but not with the isotype control antibodies, anti-gp120 F105 (Figure 2A) and anti-Tat (data not shown), demonstrating a specific but low cross-reactivity between p17 and the anti-gp41 2F5 antibody. The p17AS mutation resulted in an increase in reactivity of $2 \mathrm{~F} 5$ for p17AS compared to p17WT in vitro, as demonstrated by an approximately 2 log decrease in the apparent half maximal effective concentration $\left(\mathrm{EC}_{50}\right)$ (Figure $\mathbf{2 B}$ ). The $\mathrm{EC}_{50}$ values for $2 \mathrm{~F} 5$ against p17AS were in the same range of the $\mathrm{EC}_{50}$ for a specific anti-p17 antibody against its natural target, p17 (Figure 2B).

Thus, the gp41-specific 2F5 bnAb cross-reacted with the p17 Gag subunit. Introduction of the 2F5 epitope into p17 (p17AS) increased cross-recognition of $\mathrm{p} 17$ by the $2 \mathrm{~F} 5$ antibody, confirming that the structural context of this region of p17 was favorable for cross-recognition.

\section{Cross-Clade Anti-gp41 Responses in Rabbits Induced by p17}

Immunogenicity of p17WT and p17AS was evaluated in rabbits. Groups of three rabbits were immunized at $\mathrm{d} 0, \mathrm{~d} 28$, and $\mathrm{d} 63$ with $100 \mu \mathrm{g}$ of protein formulated on PLA particles, with serum samples taken every 2-3 weeks.

Antibody titers against the immunogen were estimated for each sampling point as the first dilution yielding a negative signal, and demonstrated elicitation of a high anti-p17 antibody titer $\left(\sim 10^{5}\right)$ by both immunogens (Figure 3A). Anti-p17 antibodies appeared to be present earlier in animals immunized with p17AS compared to p17WT, but the differences in titers at d98 were not statistically significant (Mann-Whitney test, $p=0.4)$.

To confirm that p17 could induce an anti-gp41 response, the same sera were titrated against clade B gp41 (HXB2). Anti-gp41 titers showed the same profile as anti-p17 titers, reaching at least $10^{5}$ at $\mathrm{d} 98$ (Figure 3B), demonstrating that immunization with p17 can indeed induce strong titers of antibodies able to recognize gp41. At d98, there was no statistically significant difference between the two groups (Mann-Whitney test, $p=0.4$ ), suggesting that amounts of induced anti-gp41 antibodies were not quantitatively higher when immunized with the p17AS mutant.

The cross-clade reactivity of these anti-gp41 antibodies was assessed through analysis of the sera for reactivity against gp41 fragments from different HIV-1 clades. As expected from antigp41 titer results, the serum from each animal recognized gp41 from the clade B strain (HXB2) (Figure 4), as well as strains from clades A, AE, D, and G (92UG037, 92UG024, 92TH022, and 92UG975, respectively) (Figure 4). These data indicate that the antibody response induced by 17 is able to cross-react with Env isolates from different clades around the 2F5 epitope. There was no significant difference in reactivity against the different proteins when immunized with p17WT or p17AS (Figure 4). Notably, the clade G strain, 92UG975, which exhibited the lowest signal (Figure 4), contains two mutations in the 2F5 epitope (ALDKWTS) compared to the clade B HXB2 strain used as a positive control (ELDKWAS) (27). As both mutations involve residues that participate in the 2F5/epitope interaction (25), this result suggests that the cross-reactivity of these sera targets the 

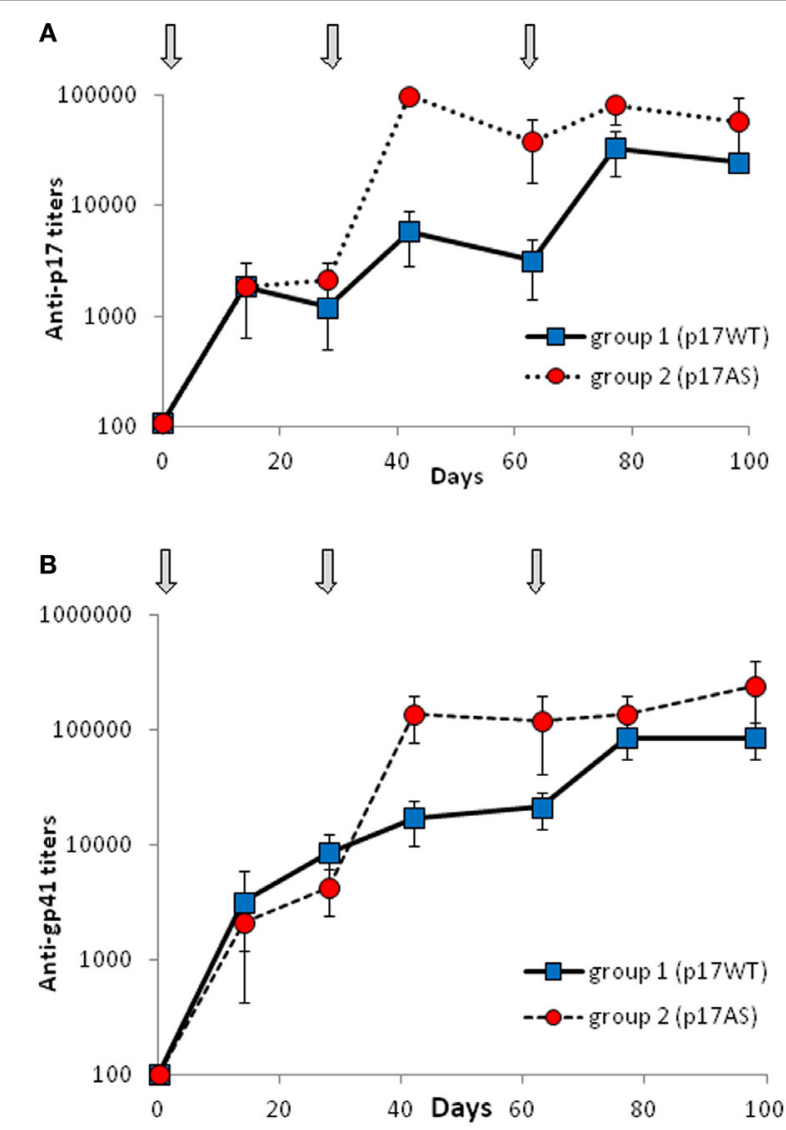

FIGURE 3 | Immunization follow-up. (A,B) Serum titration of New Zealand White rabbits immunized by $\mathrm{p} 17 \mathrm{WT}$ (blue squares, plain line) or p17AS (red circles, dotted line) against (A) the immunizing p17 protein and

(B) recombinant gp41 protein (HXB2 strain). Gray arrows indicate the dates of immunizations. Each value represents the mean of the titers of sera from the three rabbits of each group, measured individually in duplicate. Error bars represent the SD of the same measures.
2F5 epitope. Thus, immunizing rabbits with p17WT or p17AS would induce cross-clade-reactive anti-gp41 antibodies.

\section{Antibodies Induced by Immunization with p17AS Show Neutralizing Activities}

The sera of animals immunized with p17AS significantly neutralized the infectivity of viruses pseudotyped with the Env protein of the LAI strain compared to p17WT or pre-bled animals (ANOVA, $p<0.05$ and $p<0.01$, respectively) (Figure 5). This also held true for viruses pseudotyped with envelopes of primary isolates (Figure 5): p17AS-induced antibody responses able to neutralize Tier 1, clade B strains (SF162, 92US660), and one Tier 2/3, clade A isolate (92UG029), with significant neutralizing activities for animals immunized with the modified p17AS protein against these strains compared to p17WT or pre-bled animals $(p<0.05$ and $p<0.01$, respectively), reaching up to $60 \%$ of neutralization (Figure 5). Infectivity of Tier $2 / 3$, clade D isolate $92 \mathrm{UG} 001$, was only marginally affected by sera from both groups, with no significant difference between the two groups of animals (Figure 5, $p>0.5$ ).

Thus, although complete neutralization was not achieved, sera from p17AS-immunized animals had neutralizing activity against Tier 1 and Tier 2/3 isolates.

\section{DISCUSSION}

In this study, we demonstrated that the gp41-specific $2 \mathrm{~F} 5$ bnAb cross-reacted with the p17 Gag subunit. We also found that introduction of the full-length 2F5 epitope in p17 (mutant p17AS) increased this cross-reactivity in vitro. Furthermore, sera obtained after immunization with p17AS neutralized Tier 1 and Tier $2 / 3$ isolates from different clades. Neutralizing responses were detectable after three immunizations with p17AS in our study, whereas rabbits immunized with trimeric gp140 envelope proteins have detectable neutralizing responses following a

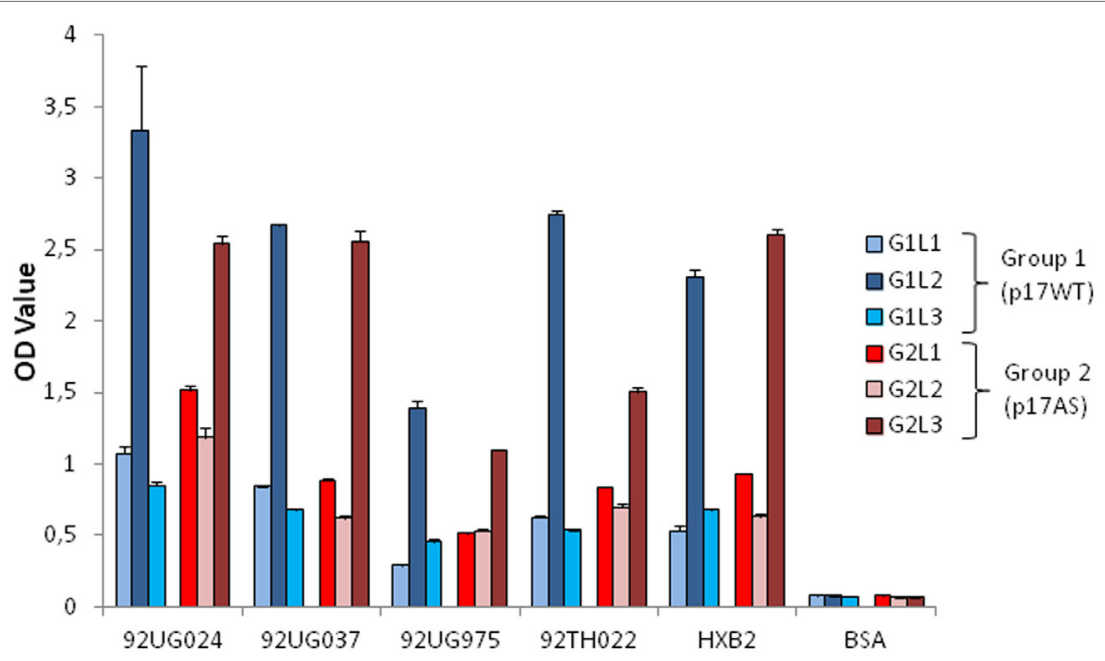

FIGURE 4 | Cross-clade reactivity of p17-induced anti-gp41 antibody responses. Recognition of recombinant gp41 fragments from different subtypes by the sera at d98 of each rabbit immunized by p17WT (blue taints) or p17AS (red taints), diluted 1/5,000. Each value represents the mean of the OD value measured individually in duplicate. Error bars represent the SD of the same measures. BSA is the negative protein control. 


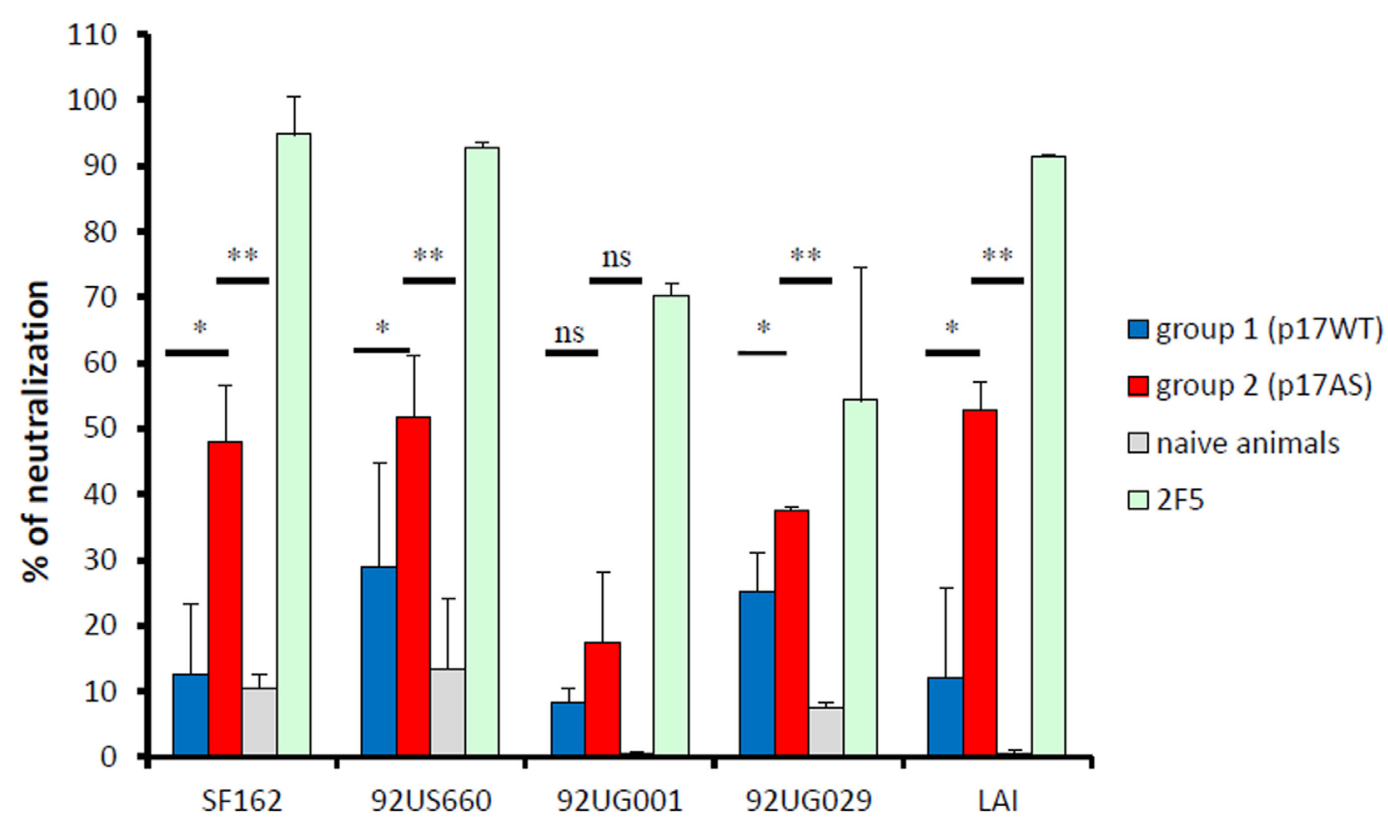

FIGURE 5 | Neutralizing activity of p17-induced anti-gp41 antibody responses. Neutralizing efficacy of purified lgG at d98 from animals immunized with p17WT (blue bars) and p17AS (red bars) against viral particles pseudotypes using envelop proteins of various isolates. Reference antibody $2 \mathrm{F5}$ (green bars) and sera from non-immunized animals (gray bars) were used as positive and negative controls, respectively. Each value represents the mean of the neutralizing efficacy of purified IgG from the three rabbits of each group, measured individually in duplicate. Error bars represent the SD of the same measures. Stars indicate significant differences between the two groups in neutralizing activity against the isolate.

fourth immunization (10). This discrepancy could be due to the heavy glycosylation pattern of gp140 which may have reduced the elicitation of anti-gp140 neutralizing antibody responses (38), while our p17 antigens were not glycosylated.

In order to avoid unnecessary animal experiments, we performed a proof-of-concept study with a small number of animals, which can now be extended to a larger cohort of animals to improve statistical power. Despite the limited number of animals, our present study clearly demonstrated that p17WT and p17AS elicited antibodies in rabbits that recognize gp41 proteins from different clades and, for p17AS, possess partial neutralizing activity. Noteworthy, these gp41-reactive, cross-clade antibodies with partial neutralizing activity were obtained without the use of Env as an immunogen. This could explain the lower neutralizing activity we observed for p17AS-induced antibodies compared to other preclinical studies in which rabbits were immunized with gp140 (10). Our results suggest that cross-clade-reactive neutralizing anti-gp41 antibodies could be developed using this p17-targeting strategy. The next step is to evaluate the dose-response efficacy of neutralizing antibodies induced by $\mathrm{p} 17$ constructs against a larger panel of viruses $(10,39)$. The quality of the antibodies induced by 17 constructs for other antiviral activities, such as antibodydependent cell-mediated cytotoxicity or virus inhibition will also be assessed.

Although some exceptions occur (40), most bnAb recognize their epitope in the lipid bilayer area of the viral particle (41). Interestingly, p17 is naturally associated with the lipid bilayer during viral replication due to the presence of an N-terminal myristoyl group (42). This location brings p17 ELDKW close to the lipid bilayer, which may enhance the induction of neutralizing antibodies. As mentioned previously, this point could not be verified as the p17 constructs were overexpressed in a bacterial system lacking natural myristoylation activity. Therefore, evaluation of cross-reactivity and immunogenicity of myristoylated forms of our p17-derived constructs is being considered.

Poly-lactic acid particles were used as an adjuvant as adsorption of the antigen is simple and reproducible, and such formulations preserve antigenicity and immunogenicity of the adsorbed antigens (43), which can also be oriented by the encapsulation of TLR ligands within the particles (44). This versatility allows for straightforward examination of the extent to which engineering of the p17 antigen, such as with the p17AS mutant, helps increase the breadth or magnitude of an induced antigp41 response (45). In parallel, structural information regarding interaction of the 2F5 antibody with the p17 constructs has been initiated to assist in structure-based engineering of the p17 antigen. Indeed, if an increase in sequence homology in p17AS increases the reactivity of 2F5 against p17, induced sera would be less reactive against isolates that contain a mutated sequence of the 2F5 epitope. Thus, increasing sequence homology while maintaining the structural environment of the 2F5 epitope in p17 will be the next step in optimization of a potent p17-derived antigen.

We demonstrated that sera obtained after immunization with p17AS neutralized infection by Tier 1 and Tier $2 / 3$ isolates in vitro. Thus, p17 antigen can be used in an epitope scaffolding approach $(46,47)$, with the advantage of being a carrier 
that possesses vaccinal properties. As p17 induces strong CTL responses, such an approach would result in generation of a multivalent candidate antigen inducing both anti-Gag and anti-gp41 responses. Similarly, epitope scaffolding using Gag p24 subunit as a carrier for Env epitopes has been suggested $(48,49)$. These previous studies are based solely on bio-computational predictions and biophysical/biochemical validations. In contrast, our approach takes advantage of the existing cross-reactivity of p17 with bnAb 2F5, and this cross-reactivity resulted in induction of anti-Env antibodies with some neutralizing efficacy in an animal model.

In conclusion, we have confirmed the natural cross-reactivity between HIV-1 p17 protein and gp41-specific 2F5 antibody which was suspected from previous studies (22). We have established the proof-of-concept that this property can be exploited to induce anti-HIV-1 neutralizing antibody responses by validating several points: first, the HIV-1 p17 protein induces anti-gp41 responses in rabbits. Second, p17 can be modified to increase its recognition by anti-gp41 antibodies in vitro. Finally, such a modified p17 induces antibodies with neutralizing activity in a rabbit model in vivo. Thus, our study paves the way for rational design of multifunctional antigens derived from $\mathrm{p} 17$ to induce both protective responses against Gag and neutralizing antibodies against gp41 as part of a vaccine formulation against HIV-1 infection.

\section{ETHICS STATEMENT}

Animals were housed and manipulated according to French standard regulatory ethical and welfare guidelines of the PLEXAN,

\section{REFERENCES}

1. Gray ES, Madiga MC, Moore PL, Mlisana K, Abdool Karim SS, Binley JM, et al. Broad neutralization of human immunodeficiency virus type 1 mediated by plasma antibodies against the gp41 membrane proximal external region. J Virol (2009) 83:11265-74. doi:10.1128/JVI.01359-09

2. Corti D, Lanzavecchia A. Broadly neutralizing antiviral antibodies. Annu Rev Immunol (2013) 31:705-42. doi:10.1146/annurev-immunol-032712-095916

3. Moore PL, Williamson C, Morris L. Virological features associated with the development of broadly neutralizing antibodies to HIV-1. Trends Microbiol (2015) 23:204-11. doi:10.1016/j.tim.2014.12.007

4. Pegu A, Hessell AJ, Mascola JR, Haigwood NL. Use of broadly neutralizing antibodies for HIV-1 prevention. Immunol Rev (2017) 275:296-312. doi:10.1111/ imr.12511

5. Wibmer CK, Moore PL, Morris L. HIV broadly neutralizing antibody targets. Curr Opin HIV AIDS (2015) 10:135-42. doi:10.1097/COH.0000000000000153

6. Kwong PD, Mascola JR, Nabel GJ. Rational design of vaccines to elicit broadly neutralizing antibodies to HIV-1. Cold Spring Harb Perpect Med (2011) 1:a007278. doi:10.1101/cshperspect.a007278

7. McCoy LE, Weiss RA. Neutralizing antibodies to HIV-1 induced by immunization. J Exp Med (2013) 210:209-23. doi:10.1084/jem.20121827

8. Lewis GK, DeVico AL, Gallo RC. Antibody persistence and T-cell balance: two key factors confronting HIV vaccine development. Proc Natl Acad Sci U S A (2014) 111:15614-21. doi:10.1073/pnas.1413550111

9. McCoy LE, Burton DR. Identification and specificity of broadly neutralizing antiodies against HIV. Immunol Rev (2017) 275:11-20. doi:10.1111/imr.12484

10. Quinnan GV Jr, Onabajo O, Zhang P, Yan L, Mattapallil JJ, Zhang Z, et al. Immunization of rabbits with highly purified, soluble, trimeric human immunodeficiency virus type 1 envelope glycoprotein induces a vigorous B cell response and broadly cross-reactive neutralization. PLoS One (2014) 9:e98060. doi:10.1371/journal.pone.0098060
Saint-Étienne (authorization no 42-218-0801), and approved by the relevant ethics committee (Comité d'Ethique en Expérimentation Animale de la Loire (CEEAL-UJM n 98), Faculté de Médecine Jacques Lisfranc, Saint-Étienne; reference 00811.02).

\section{AUTHOR CONTRIBUTIONS}

BV, SP, and CG designed the study. CG, LB-G, and LB produced the antigens and characterized in vitro cross-reactivities. $\mathrm{CP}$ and $\mathrm{CT}$ formulated the antigens. $\mathrm{FJ}, \mathrm{AE}$, and $\mathrm{BC}$ immunized the animals and performed neutralizing studies. $\mathrm{CT}$ and $\mathrm{AE}$ performed the ELISA with animal sera. BV, SP, CT, and CG analyzed the data. All authors participated to the writing of the manuscript.

\section{ACKNOWLEDGMENTS}

The authors thank Dr. R. Montserret for his help with circular dichroïsm and Dr. N. Battail-Poirot for the gift of anti-p17 8E7A3 antibody.

\section{FUNDING}

CG, BV, and SP were supported in part by the Agence Nationale de Recherche sur le SIDA (ANRS). SP and BV are supported by grants from the Fondation Pierre Bergé-Sidaction, FP7 European grants CUT'HIVAC (No. 241904) and ADITEC (No. 280873), and HIVERA support (HIVNANOVA).

11. Hessell AJ, Malherbe DC, Pissani F, McBurney S, Krebs SJ, Gomes M, et al. Achieving potent autologous neutralizing antibodies responses against Tier 2 HIV-1 viruses by strategic selection of envelopes immunogens. J Immunol (2016) 196:3064-78. doi:10.4049/jimmunol.1500527

12. Escolano A, Steichen JM, Dosenovic P, Kulp DW, Golijanin J, Sok D, et al. Sequential immunization elicits broadly neutralizing anti-HIV-1 antibodies in Ig knock-in mice. Cell (2016) 166:1445-58. doi:10.1016/j.cell.2016. 07.030

13. Haynes BF, Burton DR. Developing an HIV vaccine. Science (2017) 355: 1129-30. doi:10.1126/science.aan0662

14. Inagaki $\mathrm{N}$, Takeuchi $\mathrm{H}$, Yokoyama $\mathrm{M}$, Sato $\mathrm{H}$, Ryo $\mathrm{A}$, Yamamoto $\mathrm{H}$, et al. A structural constraint for functional interaction between $\mathrm{N}$-terminal and C-terminal domains in simian immunodeficiency virus capsid proteins. Retrovirology (2010) 7:90. doi:10.1186/1742-4690-7-90

15. Yu XG, Shang H, Addo MM, Eldridge RL, Phillips MN, Feeney ME, et al. Important contribution of p15 Gag-specific responses to the total Gag-specific CTL responses. AIDS (2002) 16:321-8. doi:10.1097/00002030200202150-00002

16. Kiepiela P, Ngumbela K, Thobakgale C, Ramduth D, Honeyborne I, Moodley E, et al. CD8+ T-cell responses to different HIV proteins have discordant associations with viral load. Nat Med (2007) 13:46-53. doi:10.1038/ nm 1520

17. Radebe M, Gounder K, Mokgoro M, Ndhlovu ZM, Mncube Z, Mkhize L, et al. Broad and persistent Gag-specific CD8+ T-cell responses are associated with viral control but rarely drive viral escape during primary HIV-1 infection. AIDS (2015) 29:23-33. doi:10.1097/QAD.0000000000000508

18. Mann JK, Ndung'u T. HIV-1 vaccine immunogen design strategies. Virol J (2015) 12:3. doi:10.1186/s12985-014-0221-0

19. Fiorentini S, Giagulli C, Caccuri F, Magiera AK, Caruso A. HIV-1 matrix protein p17: a candidate antigen for therapeutic vaccines against AIDS. Pharmacol Ther (2010) 128:433-44. doi:10.1016/j.pharmthera.2010.08.005 
20. Caccuri F, Marsico S, Fiorentini S, Caruso A, Giagulli C. HIV-1 matrix protein p17 and its receptors. Curr Drug Targets (2016) 17:23-32. doi:10.2174/13894 50116666150825110840

21. Buratti E, Tisminetzky SG, D'Agaro P, Baralle FE. A neutralizing monoclonal antibody previously mapped exclusively on human immunodeficiency virus type 1 gp 41 recognizes an epitope in p17 sharing the core sequence IEEE. J Virol (1997) 71:2457-62.

22. Papsidero LD, Sheu M, Ruscetti FW. Human immunodeficiency virus type 1-neutralizing monoclonal antibodies which react with p17 core protein: characterization and epitope mapping. J Virol (1989) 63:267-72.

23. Muster T, Steindl F, Purtscher M, Trkola A, Klima A, Himmler G, et al. A conserved neutralizing epitope on gp41 of human immunodeficiency virus type 1. J Virol (1993) 67:6642-7.

24. Muster T, Guinea R, Trkola A, Purtscher M, Klima A, Steindl F, et al. Crossneutralizing activity against divergent human immunodeficiency virus type 1 isolates induced by the gp41 sequence ELDKWAS. J Virol (1994) 68:4031-4.

25. Ofek G, Tang M, Sambor A, Katinger H, Mascola JR, Wyatt R, et al. Structure and mechanistic analysis of the anti-human immunodeficiency virus type 1 antibody 2F5 in complex with its gp41 epitope. J Virol (2004) 78:10724-37. doi:10.1128/JVI.78.19.10724-10737.2004

26. Connor RI, Sheridan KE, Lai C, Zhang L, Ho DD. Characterization of the functional properties of env genes from long-term survivors of human immunodeficiency virus type 1 infection. J Virol (1996) 70:5306-11.

27. Kuiken CL, Foley B, Leitner T, Hahn BH, Apetrei C, Mizrachi I, et al. HIV Sequence Compendium 2010. Los Alamos: Theoretical Biology and Biophysics, Los Alamos National Laboratory (2010).

28. Hill CP, Worthylake D, Bancroft DP, Christensen AM, Sundquist WI. Crystal structures of the trimeric human immunodeficiency virus type 1 matrix protein: implications for membrane association and assembly. Proc Natl Acad Sci U S A (1996) 93:3099-104. doi:10.1073/pnas.93.7.3099

29. Kwon YD, Georgiev IS, Ofek G, Zhang B, Asokan M, Bailer RT, et al. Optimization of the solubility of HIV-1-neutralizing antibody 10E8 through somatic variation and structure-based design. J Virol (2016) 90:5899-914. doi:10.1128/JVI.03246-15

30. Robert X, Gouet P. Deciphering key features in protein structures with the new ENDscript server. Nucleic Acids Res (2014) 42:W320-4. doi:10.1093/nar/ gku316

31. Serrière J, Robert X, Perez M, Gouet P, Guillon C. Biophysical characterization and crystal structure of the Feline Immunodeficiency Virus p15 matrix protein. Retrovirology (2013) 10:64. doi:10.1186/1742-4690-10-64

32. Foucault M, Mayol K, Receveur-Bréchot V, Bussat M-C, Klinguer-Hamour C, Verrier B, et al. UV and X-ray structural studies of a 101-residue long Tat protein from a HIV-1 primary isolate and of its mutated, detoxified, vaccine candidate. Proteins (2010) 78:1441-56. doi:10.1002/prot.22661

33. Wilkinson RA, Piscitelli C, Teintze M, Cavacini LA, Posner MR, Lawrence CM. Structure of the Fab fragment of F105, a broadly reactive anti-human immunodeficiency virus (HIV) antibody that recognizes the CD4 binding site of HIV type 1 gp120. J Virol (2005) 79:13060-9. doi:10.1128/JVI.79.20.1306013069.2005

34. Serrière J, Dugua J-M, Bossus $\mathrm{M}$, Verrier B, Haser R, Gouet $\mathrm{P}$, et al. Fab'-induced folding of antigenic N-terminal peptides from intrinsically unstructured HIV-1 Tat protein revealed by X-ray crystallography. J Mol Biol (2011) 405:33-42. doi:10.1016/j.jmb.2010.10.033

35. Guillon C, Mayol K, Terrat C, Compagnon C, Primard C, Charles M-H, et al. Formulation of HIV-1 Tat and p24 antigens by PLA nanoparticles or MF59 impacts the breadth, but not the magnitude, of serum and faecal antibody responses in rabbits. Vaccine (2007) 25:7491-501. doi:10.1016/j. vaccine.2007.08.060

36. Benjelloun F, Dawood R, Urcuqui-Inchima S, Rochereau N, Chanut B, Verrier B, et al. Secretory IgA specific for MPER can protect from HIV-1 infection in vitro. AIDS (2013) 27:1992-5. doi:10.1097/QAD.0b013e3283632eal
37. Dawood R, Benjelloun F, Pin JJ, Kone A, Chanut B, Jospin F, et al. Generation of HIV-1 potent and broad neutralizing antibodies by immunization with postfusion HR1/HR2 complex. AIDS (2013) 27:717-30. doi:10.1097/ QAD.0b013e32835cfca5

38. Zhou T, Doria-Rose NA, Cheng C, Stewart-Jones GBE, Chuang G-Y, Chambers $\mathrm{M}$, et al. Quantification of the impact of the HIV-1-glycan shield on antibody elicitation. Cell Rep (2017) 19:719-32. doi:10.1016/j. celrep.2017.04.013

39. deCamp A, Hraber P, Bailer RT, Seaman MS, Ochsenbauer C, Kappes J, et al. Global panel of HIV-1 Env reference strains for standardized assessments of vaccine-elicited neutralizing antibodies. J Virol (2014) 88:2489-507. doi:10.1128/JVI.02853-13

40. Huang J, Ofek G, Laub L, Louder MK, Doria-Rose NA, Longo NS, et al. Broad and potent neutralization of HIV-1 by a gp41-specific human antibody. Nature (2012) 491:406-12. doi:10.1038/nature11544

41. Dennison SM, Stewart SM, Stempel KC, Liao HX, Haynes BF, Alam SM. Stable docking of neutralizing human immunodeficiency virus type $1 \mathrm{gp} 41$ membrane-proximal external region monoclonal antibodies $2 \mathrm{~F} 5$ and $4 \mathrm{E} 10$ is dependent on the membrane immersion depth of their epitope regions. J Virol (2009) 83:10211-23. doi:10.1128/JVI.00571-09

42. Tang C, Loeliger E, Luncsford P, Kinde I, Beckett D, Summers MF. Entropic switch regulates myristate exposure in the HIV-1 matrix protein. Proc Natl Acad Sci U S A (2004) 101:517-22. doi:10.1073/pnas.0305665101

43. Lamalle-Bernard D, Munier S, Compagnon C, Charles MH, Kalyanaraman VS, Delair T, et al. Coadsorption of HIV-1 p24 and gp120 proteins to surfactantfree anionic PLA nanoparticles preserves antigenicity and immunogenicity. J Control Release (2006) 115:57-67. doi:10.1016/j.jconrel.2006. 07.006

44. Pavot V, Climent N, Rochereau N, Garcia F, Genin C, Tiraby G, et al. Directing vaccine immune responses to mucosa by nanosized particulate carriers encapsulating NOD ligands. Biomaterials (2016) 75:327-39. doi:10.1016/j. biomaterials.2015.10.034

45. Pavot V, Berthet M, Rességuier J, Legaz S, Handké N, Gilbert SC, et al. Poly(lactic acid) and poly(lactic-co-glycolic acid) particles as versatile carrier platforms for vaccine delivery. Nanomedicine (2014) 9:2703-18. doi:10.2217/ nnm. 14.156

46. Ofek G, Guenaga FJ, Schief WR, Skinner J, Baker D, Wyatt R, et al. Elicitation of structure-specific antibodies by epitope scaffolds. Proc Natl Acad Sci U S A (2010) 107:17880-7. doi:10.1073/pnas.1004728107

47. Correia BE, Ban YE, Holmes MA, Xu H, Ellingson K, Kraft Z, et al. Computational design of epitope-scaffolds allows induction of antibodies specific for a poorly immunogenic HIV vaccine epitope. Structure (2010) 18:1116-26. doi:10.1016/j.str.2010.06.010

48. Tagliamonte M, Marasco D, Ruggiero A, De Stradis A, Tortevoye P, Totrov M, et al. HIV p24 as scaffold for presenting conformational HIV Env antigens. PLoS One (2012) 7:e43318. doi:10.1371/journal.pone.0043318

49. Buonaguro L, Tagliamonte M, Tornesello ML, Buonaguro FM. Can HIV p24 be a suitable scaffold for presenting Env antigens? Clin Vaccine Immunol (2011) 18:2003-4. doi:10.1128/CVI.05326-11

Conflict of Interest Statement: The authors declare that the research was conducted in the absence of any commercial or financial relationships that could be construed as a potential conflict of interest.

Copyright (๑) 2017 Verrier, Paul, Terrat, Bastide, Ensinas, Phelip, Chanut, BulensGrassigny, Jospin and Guillon. This is an open-access article distributed under the terms of the Creative Commons Attribution License (CC BY). The use, distribution or reproduction in other forums is permitted, provided the original author(s) or licensor are credited and that the original publication in this journal is cited, in accordance with accepted academic practice. No use, distribution or reproduction is permitted which does not comply with these terms. 